\title{
Linear Static Examination of a Composite Base Structure
}

\author{
N Prabhu Kishore, Siva Kumar Ellapan, Alekhya N
}

\begin{abstract}
The base structure of the spacecraft connects the satellite with the launch vehicle and it is the main load bearing member. To satisfy the structural requirements, advanced materials are used commonly to manufacture the mechanical load bearing members. The paper deals with the analysis of the base structure of the spacecraft using a combination of metal with the composite materials like CFRP (Carbon Fiber Reinforced Plastic). Analysis is done for base structure of the spacecraft by varying materials in ANSYS 14.5 for each ring. The variation of the materials is done on the insert ring of the base structure along the height in five different ways. The analysis done suggest that the combination of Ti and CFRP ensures lower deformation and weighed $7.34 \mathrm{~kg}$ achieving a mass saving of $35 \%$ on the existing structure.
\end{abstract}

Keywords : ANSYS,Base Structure, CFRP, Linear static analysis

\section{INTRODUCTION}

Preparation of the composite materials is used to increase the rigidity of the structure and also to reduce the mass of the object [5]. The interface ring is metallic in almost in every case. These structures are a significant part in spacecraft mass [2]. The base structure of Bepi Colombo spacecraft is made of CFRP, Titanium at the insert (insert ring) and aluminum alloy at the base. Normally, AL alloys are used for the manufacturing of aircrafts. In these days composites play a major role in the aircraft industry. Fibre composites replaced the metals in most of the cases. These composite materials like CFRP can obtain high stiffness to weight ratio when compared to metals. Use of the advanced materials in the aerospace has become most common and there searchers are looking towards the materials that can be stronger and be light in weight and that can also resist the highest thermal loads. Structural optimization techniques were used by many to find the performance of the composites when applied to the aerospace components [6,7]. CFRP and GFRP are the common materials which are used for aerospace applications [10]. The CFRP can replace the metals like aluminum but the main disadvantage of it is it cannot withstand the high amount of thermal loads. So maximum they are used for the structural strength.

Revised Manuscript Received on December 30, 2019.

* Correspondence Author

N Prabhu Kishore*, Associate Professor, Department of Mechanical Engineering, MLR Institute of Technology, Hyderabad,

Siva Kumar Ellapan, Professor, Department of Mechanical Engineering, MLR Institute of Technology, Hyderabad,

Alekhya N,Assistant Professor, Department of Aeronautical Engineering, MLR Institute of Technology, Hyderabad,

(C) The Authors. Published by Blue Eyes Intelligence Engineering and Sciences Publication (BEIESP). This is an open access article under the CC BY-NC-ND license (http://creativecommons.org/licenses/by-nc-nd/4.0/)
All materials degrade over time and are subject to wear, due to extreme conditions and subject to wear in space missions this is a major challenge to overcome. The damaged materials are least possible to be repairable. To overcome this difficulty Self healing materials are very helpful for restoring the properties like Mechanical when damaged, by which we can enhance the lifetime of the structure. The CFRP materials are self healing which have the flexural strengths [1].

As the base structure is the main load bearing member, it is made of high strength materials like aluminum alloy and titanium alloy. But that additional strength of the material adds weight to the structure. In order to reduce the weight the base structure is made with CFRP except the titanium insert ring and the separation plane ring (base). The insert ring is the load bearing ring which is next to the attachment of the spacecraft to the base structure. So it should always be made with a highly strength materials. This paper is mainly dealing with this insert ring. The metal is replaced with CFRP as the strength of CFRP is more and is light in weight [9].

\section{MODELLING AND ANALYSIS}

The base structure is divided into some of the parts in the cross sectional view such that the model can be easily analyzed. The cross sectional view of the base structure is shown in the figure 1 which shows the parts of the base structure. The names of teach part is shown in the table 1 . The base structure is modeled in ANSYS and then analyzed statically for finding the strength of the CFRP material whether it can be used for the spacecraft applications.

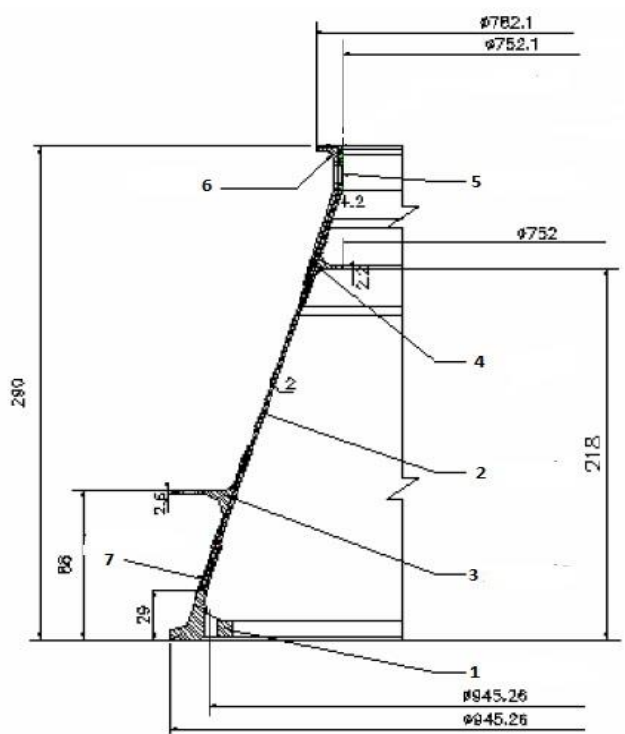

Figure 1: Cross section with part numbers 


\section{Linear Static Examination of a Composite Base Structure}

\section{MATERIAL SELECTION AND APPLYING THE LAY UPS:}

The complete structure is commonly made with aluminum alloys. But in this paper the complete base structure is made with CFRP except the base and the insert ring. The insert ring is made with CFRP and Titanium alloy. The interface ring is applied with CFRP (M55J/914 unidirectional Prepeg and G837/914 Bi-directional) fabric and fitted with an aluminum ring liner in its inner diameter at top region to facilitate interface requirement for the payload attachment. The bottom ring is applied with the aluminum as to meet the launch vehicle requirements. The CFRP interface ring has a layered construction and after preliminary analysis, lay-up sequence has selected as $\left[\# 0_{2} / 0 / 90 / 0 / 90 /-45 /-45 / 90 / 0 / 90 / 0 / 90 / 0 / 0\right]_{s}$ for entire regions [11]. Here \# refers to the Bi-directional fabrics. Fabrics are selected at the inner and outer surfaces for easy of fabrication process.

As this structure consists of many parts each part is layered with different layups. The main sections which use composites are 5 sections and the other two sections use the aluminum alloy and titanium alloy. Each section is given different lay ups. For all the five cases, the same bi directional fabrics are used. For the insert ring, the composite CFRP is used with same directional orientation.

Table 1: Lay ups for the CFRP structure

\begin{tabular}{|l|l|l|l|}
\hline $\begin{array}{l}\text { Name of } \\
\text { the section }\end{array}$ & $\begin{array}{l}\text { Part } \\
\text { number }\end{array}$ & $\begin{array}{l}\text { Section } \\
\text { number }\end{array}$ & Lay up \\
\hline $\begin{array}{l}\text { CFRP } \\
\text { Main } \\
\text { Structure }\end{array}$ & 2 & 1 & \\
\hline Outer Lip & 3 & 2 & {$\left[\# 0_{2} / 0_{2} /+45 /-45 / 0_{4}\right]_{\mathrm{s}}$} \\
\hline Inner Lip & 4 & 3 & {$\left[\# 0_{2} / 90_{2} / 0_{2} /+45 /-45 / 0_{2} / 90 / 0_{2}\right]_{\mathrm{s}}$} \\
\hline Top Lip & 6 & 4 & {$\left[\# 0_{2} / 0 / 90 / 0 /+45 /-45 / 0_{4}\right]_{\mathrm{s}}$} \\
\hline Stiffener & 7 & 5 & {$\left[\# 0_{2} / 0 / 90_{\mathrm{s}} / \# 0\right]_{\mathrm{s}}$} \\
\hline
\end{tabular}

The base structure is modeled using the key points in ANSYS and then generate the volume for each part as shown in figure 2

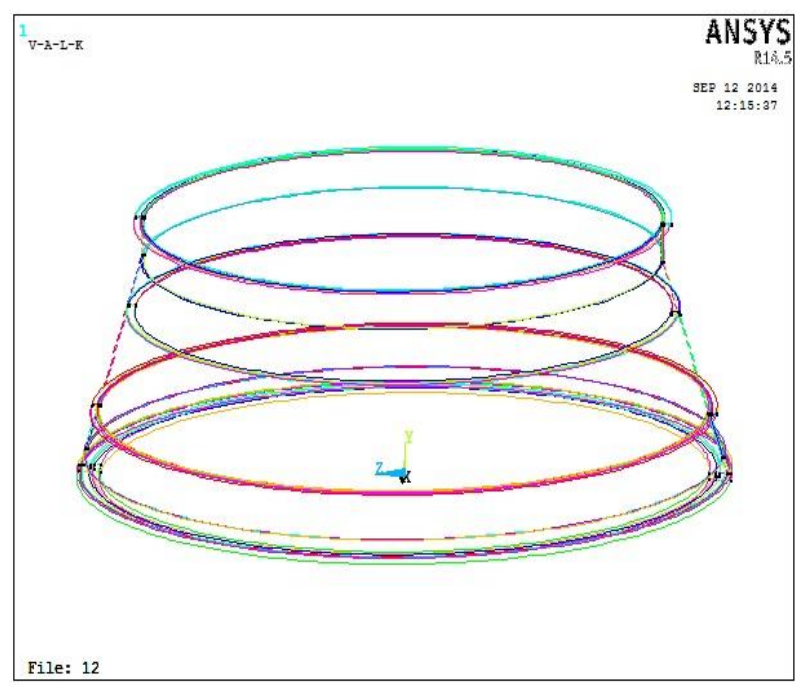

Figure2: Volume generated through the ANSYS

The volume generated is applied with boundary conditions, finally loads are applied. The loads are shown in figure 3 . This volume is then meshed and is analyzed for the performance.

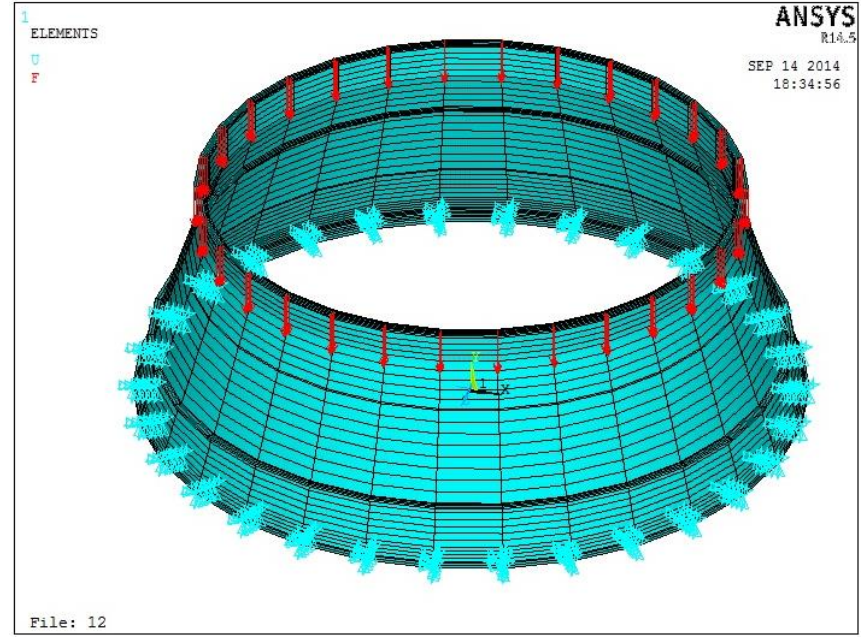

Figure3: Base structure applied with boundary conditions

\section{RESULT AND DISCUSSION}

\subsection{Analytical Results:}

The base structure modeled and is been analyzed by varying the material along the height of the ring. The figures 4 show the variation of the stresses and the deformation. Five cases are taken for analysis so as to ensure which material is suitable for the insert ring.

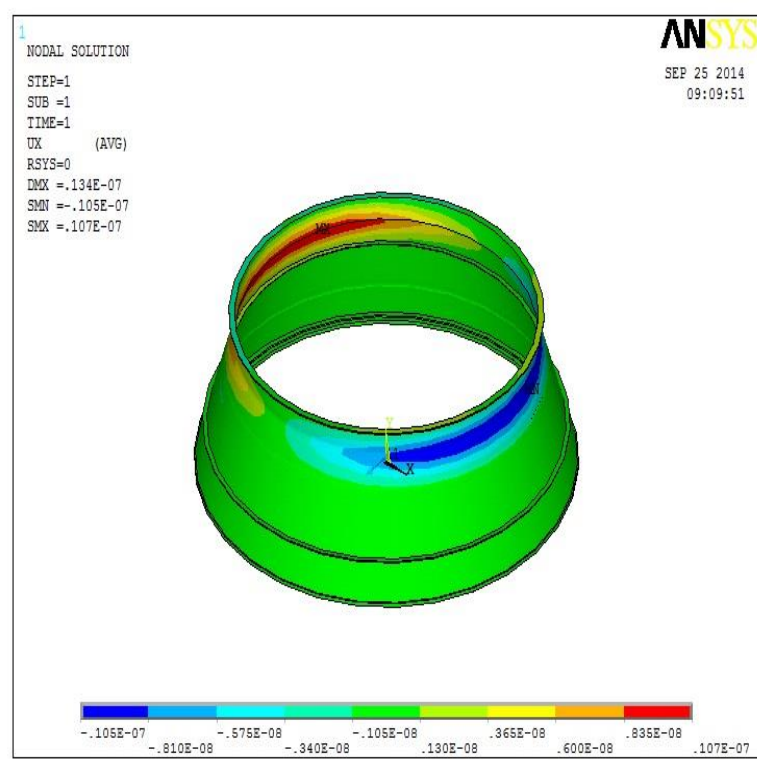

Figure 4: Variation of stress deformation

\subsection{Comparison of five cases:}

The base structure is analyzed for five cases based on the height of the insert ring. The stress deformation is considered for the five cases. The insert ring is varied with CFRP and titanium by total height, till $278 \mathrm{~mm}$, till 254mm, till 266mm, total CFRP by removing titanium.

For each case the structure is analyzed and the Von Mises stress deformation for the five cases are shown in the figure 5 .

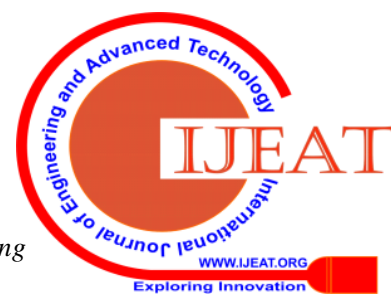




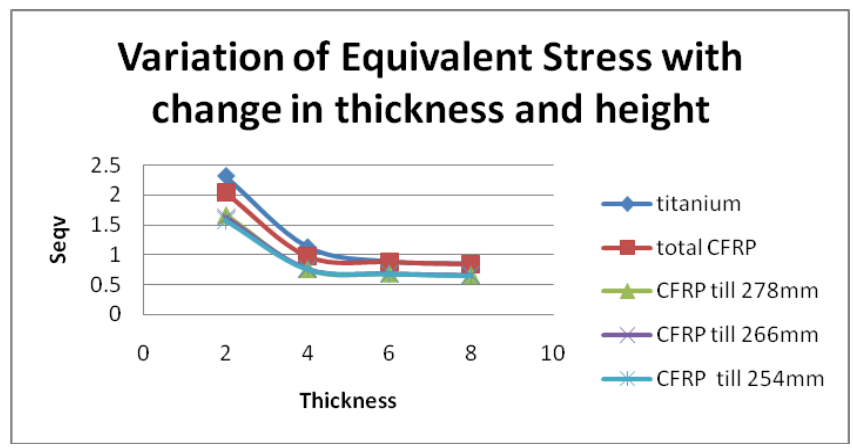

Figure 5: Variation of Von Mises stress with thickness and material

\subsection{Mass:}

The mass of complete spacecraft can be reduced by reducing the mass of the base structure. We can obtain $5 \%$ reduction in mass of base structure when replacing with CFRP structure. The performance of space craft can be increased by reducing the mass. The insert can't be replaced with composite.

Table2. Change of mass

\begin{tabular}{|l|l|l|}
\hline $\begin{array}{l}\text { Existing } \\
\text { design }\end{array}$ & Optimized design & $\begin{array}{l}\text { Model of CFRP } \\
\text { including Ti insert } \\
\text { and aluminum } \\
\text { base }\end{array}$ \\
\hline $8.53 \mathrm{Kg}$ & $7.75 \mathrm{Kg}$ & $7.34 \mathrm{Kg}$ \\
\hline
\end{tabular}

\section{CONCLUSION}

The analytical results are approximately equal to theoretical results. It is observed that combination of CFRP and $\mathrm{Ti}$ composite showed less Deformation and Higher Strength when compared to complete CFRP or complete Ti. Hence, the metallic part can be replaced by composite instead of complete CFRP or complete Ti, which is also reducing mass of the base structure approximately by $8 \%$.

\section{REFERENCES}

1. B. Aissa, K. Tagziria, E. Haddad, W. Jamroz, J. Loiseaau, A. Higgins, M. Asgar-khan, S.V. Hoa, P.G.Merle, D. Therriault, F. Rosei, “ The Self Healing Capability of Carbon Fibre Composite Structures Subjected to Hypervelocity Impacts Simulating Orbital Space Debris", ISRN Nano materials, Volume 2012

2. K.K. Sairajan, P.S. Nair, "Design of low mass dimensionally stable composite base structure for a spacecraft", Composites: Part B, Volume 2010.

3. Diletta Falconieri, Francesco Franco, "The effect of titanium insert repairs on the static strength of CFRP coupons and joints", Volume 134, 15 December 2015, Pages 799-810.

4. A. Fink, P.P. Camanho, J.M. Andrés, E. Pfeiffer d, A. Obst, "Hybrid CFRP/titanium bolted joints: Performance assessment and application to a spacecraft payload adaptor", Composites Science and Technology November 2009 page. no: 305-317.

5. N Prabhu Kishore, Alekhya N, "Reduction of Mass for Base Structure of a Spacecraft using CFRP", International Journal of Innovative Research in Science, Engineering and Technology, Vol. 4, Issue 8, August 2015, pg.no:7237-7243.

6. Alekhya N, N Prabhu Kishore, "Performance Comparison of GFRP Composite I Section with an Aluminum I Section", International Journal of Civil Engineering and Technology, Vol 8, Issue 4, April 2017, pg.no:278-286.

7. N Madhavi, K. Sreelakshmi, M. Satyanarayana Gupta, "Evaluation of Ply Orientation on Failure of Composites", International Journal of Civil Engineering and Technology, Vol 8, Issue 5, May 2017, pg.no:409-417.

8. M. Satyanarayana Gupta, K. Shiva Shankar, "Evaluation of Electro-Mechanical Properties of Friction Stir Welded AL/CU Bimetallic Lap Joints", Vol8, Issue 4, April 2017, pg.no:1967-1976.

\section{AUTHORS PROFILE}

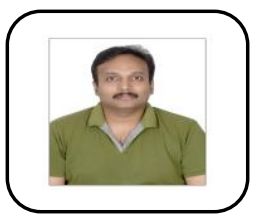

N. Prabhu Kishore is currently working as a Associate Professor in the Department of Mechanical Engineering at the MLR Institute of Technology, Hyderabad, India. He has 8 years of teaching experience and 5 years of Industry Experience in SAP-BI-IP. His current research interests include Internal Combustion Engines, Heat Transfer, and Non-Conventional Energy Sources. He has published research papers in reputed international journals which includes Scopus Journals, Elsevier. He is a Life Member of the Indian Society for Technical Education (ISTE) and a member in SAE International. Published Textbooks of Titles "An Introduction to Active Learning Strategies" and "Aircraft Computer Aided Drafting”. Certified BYST Mentor, Trained by ISB in Entrepreneurship program.

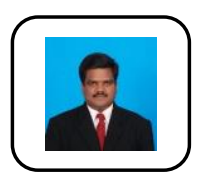

Dr.E.Sivakumar was born in Tamil Nadu, India, in 1978. He received the B.E. degree in Mechanica Engineering from the University of Madras, Chennai, India, in 1999, and the M.E. degree in Thermal Power Engineering from Annamalai University, Chidambaram, Tamil Nadu, India in 2004 and Ph.D. degree in Mechanical Engineering from the Anna University, Chennai, India, in 2017. He has 18 years of experience in engineering education at various positions, presently working as a Professor in Mechanical Engineering department in MLR Institute of Technology, Hyderabad. His current research interests include Internal Combustion Engines, Heat Transfer, and Non-Conventional Energy Sources. He has published more than 20 papers in various science index journals like Elsevier, Springer and Taylor and Francis. Dr.E.Sivakumar is a Life Member of the Indian Society for Technical Education (ISTE), and the National Institution of Quality and Reliability.

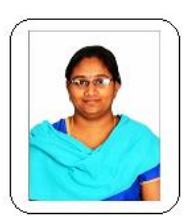

N. Alekhya is currently working as a Assistant Professor in the Department of Aeronautical Engineering at the MLR Institute of Technology, Hyderabad, India. Completed M.Tech in 2012 from JNTU Hyderabad. She has 7 years of teaching experience.She as worked Organizing Secretary for an International Conference(ICAAMM). She has published research papers in reputed international journals which includes Scopus Journals, Elsevier. She is a Life Member of the Indian Society for Technical Education (ISTE) and a member in SAE International. Published Textbooks of Titles "An Introduction to Active Learning Strategies" and "Aircraft Computer Aided Drafting". Her area of interest is in Composites related to Aerospace materials like CFRP . 